\title{
A knowledge-based material selector using Quality Function Deployment principles
}

\author{
Régis Kovacs Scalice, Gabriel Casagrande Brascher, Daniela Becker \\ Santa Catarina State University \\ e-mail: rks@joinville.udesc.br
}

\begin{abstract}
Materials selection in product development is an important task. The wrong choice of material can increase the cost of the product and/or lead to failure in the field. Therefore, during the development of a product, a suitable material must be selected based on product requirements and materials properties. This paper proposes a methodology for materials selection based on the principles of Quality Function Deployment (QFD). It relates design requirements for each component with materials properties (Assessment Matrix) and, later, performs materials selection based on these materials properties (Selection Matrix). Two examples are provided to demonstrate and validate the effectiveness and simplicity of the method proposed. Results are in agreement with other methods found in the literature and demonstrate the easiness of use of the method.
\end{abstract}

Keywords: materials selection, QFD, materials properties.

\section{Introduction}

Materials selection is a task accomplished almost every day by companies that develop or improve their products. This activity can be carried out having multiple objectives, such as: cost reduction, meeting new service conditions, weight reduction, process, new materials and aesthetic design (FERRANTE; SANTOS; CASTRO, 2000). It is estimated that there are more than 80,000 materials in the world including several types of metallic alloys and nonmetallic engineering materials (CHATTERJEE; ATHAWALE; CHAKRABORTY, 2011). With this assortment of materials, selecting one is a challenge. The selection of the best material involves a large number of factors, such as functional requirements, cost and manufacturing process (LJUNGBERG; EDWARDS, 2003; DENG; EDWARDS, 2007). The wrong choice of material frequently involves high costs and may lead to product failure. Therefore, designers need to identify and select the appropriate material for each product to have the lowest cost with specific performance for each application.

The first step in the process of materials selection is to specify the performance requirements of the component, relating with main characteristics of the materials and processing requirements. Consequently, some materials can be eliminated and others may be chosen as likely candidates. The relevant properties of materials are identified and classified in order of importance (CHATTERJEE; ATHAWALE; CHAKRABORTY, 2009). It is recommended adoption of a formal methodology by which materials are ranked according to some criteria to materials selection when a large number of materials is involved and/or conflicting demands are present. There are many techniques can be employed for the purpose (SANTOS; FERRANTE, 2003).

Several methods can be found to systematize the selection of materials. Ashby and co-workers (ASBHY, 1989; ASBHY, 1992; ESAWI; ASHBY, 1996) introduced charts for selection of materials that relate two specific material properties and cluster the materials classes. There are two steps in this method. First, primary limitations are imposed by the project to a specific materials list. Second, the performance index is applied to maximize properties.

An alternative method is the Weighted Properties Method (WPM) that is used when several properties should be considered simultaneously. This numerical method sorts the materials based on their performance indices, calculated using simple math (FARAG, 1997). As the number of alternatives increases, the amount of computation increases rapidly and the computational procedures become more elaborate. Dehgnan-Manshadi et al. (2007) proposed a modification in WPM through a combination of a nonlinear approach to sort properties by the modified digital-logical method. According to the authors, this method presents a more reasonable material selection method than WPM. In addition, Rao (2006) introduced a new methodology using a graphical approach and a matrix.

Some authors used the fuzzy logic to develop methodologies for materials selection. Liao (1996) has introduced a decision-making method using fuzzy set theory. Chen(1997) employed a fuzzy ambient, where the importance 
weights of different criteria and the ratings of various alternatives under different criteria were assessed in linguistic terms using fuzzy numbers. Most methods suggested in the literature work well for quantitative properties. Khabbaz et al. (2009) suggested a method based on simplified Fuzzy Logic as a tool for selecting materials with properties when qualitative measures are also considered, and furthermore, according to the authors, with this method the math involved in traditional methods is reduced.

Many authors use adaptations of the method of multi-criteria decision making (MCDM) for material selection. Chatterjee, Athawale and Chakraborty (2009) suggested resolving the problem of material selection using two approaches of MCDM. The first approach is "VIse Kriterijumska Optimizacija Krompromisno Resenje" (VIKOR), a compromise ranking method. The second approach is "ELimination and Et Choice Translating REality" (ELECTRE), an outranking method. These two methods were used to sort the materials in which some requirements were considered simultaneously. These methods were effective for the choice of materials.

Another methodology based on the method of multi-criteria decision-making (MCDM) was presented by Jahan et al. (2010), which is a simpler adaptation based on the same method and includes the qualitative properties in material selection for a particular product. In another study Chatterjee, Athawale and Chakraborty (2011) present two other methods based on MCDM: complex proportional assessment (COPRAS) and evaluation of mixed data (EVAMIX). These two methods are used to classify a set of materials, when many requirements are considered simultaneously, and also proved efficient for problems of material selection involving a large number of qualitative and quantitative requirements with various alternatives of materials. Rao and Patel (2010) suggested a method based on MCDM considering importance weights of the attributes of the project as well as the subjective preferences of decision making to decide the importance of each design requirement, and use fuzzy logic to convert the qualitative attribute into quantitative attributes. According to the authors, this methodology is logical and simple compared to other methods based on MCDM.

Akao (1990) is widely regarded as the father of quality function deployment (QFD). His work was first implemented at the Mitsubishi Heavy Industries Kobe Shipyard in 1972. The interest in QFD in the West was increased as indicated by the reports of achievements made by Toyota through its application between 1977 and 1984 . These included a reduction in the product development cost by $61 \%$, a decrease in the development cycle by one third and practical elimination of rust related warranty problems. Quality function deployment is a well known systematic process used for motivating an organization to focus on its customers (CHAKRABORTY; DEY, 2007). However, QFD can be considered a complimentary method for determining how and where priorities are to be assigned in the product development, where the intent is to employ objective procedures in increasing the detailed design throughout the development of the product (CHEN; YEH; YANG, 2006). Hence the QFD presents a tool that can be used in all engineering stages and can be applied mainly at the conceptual design stage (MAYYAS et al., 2011). A limited number of paper using QFD in materials selection are found in literature. Among these limited manuscripts, we can cited Mayyas et al. (2011) discussed the usage of multi-attribute decision making tools to assist in the material selection for vehicular structures, using the House of Quality (HoQ) and Analytical Hierarchy Process (AHP).

This work proposes a procedure for material selection based on the principles of Quality Function Deployment (QFD), a method widely known and used in the area of product development, which makes their utilization easier, reducing the time needed to learn new methods.

\section{Development and structure of the proposed method}

\subsection{Quality Function Deployment (QFD)}

The Quality Function Deployment (QFD) is "[...] a way to systematically communicate information related to the quality and orderly explain the related work to the achievement of quality [...]" (CHENG; MELO FILHO, 2007, p. 44). For Cheng and Melo Filho (2007, 2008), the process of quality deployment can be performed in different operational units, which are listed below according to their level of complexity:

- Table: the simplest operational unit, used to understand the problem. Can be accomplished through a tree diagram;

- Matrix: correlates two tables. The House of Quality is an example of a matrix, which correlates the requirements of customers with the quality requirements of a particular product, service or process;

- Conceptual Model: is a mapping of how deployments should occur among tables and matrices to achieve the completion of the desired tables; and

- Standard: corresponds to the unfolding information generated for communication with different areas of an organization.

The House of Quality (HoQ) frequently is the first matrix constructed during a QFD analysis. Due to its connection to the customer requirements, it is often considered central to the Quality Deployment. The HoQ is the matrix that aims to translate customer requirements into technical requirements (Figure 1). This process is called extraction 
and could be performed several times during the design process, following a specific conceptual model.

A Conceptual Model, according to Cheng and Melo Filho (2007, 2008), is a collection of tables and matrices which represents the way that must be followed to achieve the design goals (e.g. Figure 2). It can be defined as a graphic form for representing cause-effect relationships of required quality, or other effects, with cause factors that contribute to the formation of the product, according to a desired logic.

Akao (1990) presented a conceptual model for Quality Deployment that includes technology, costs and reliability. Rahimi and Weidner (2002) redefined the traditional sequence of HoQ matrices to include the structuring of design objectives and alternatives based on a multi-objective decision hierarchy. The approach taken is the incorporation of a Design for Environment (DfE) 'Environmentally Responsible Product Assessment Matrix' into Quality Function Deployment's (QFD's) 'House of Quality' (HoQ) matrices. Yeh, Huang and $\mathrm{Yu}$ (2011) proposed a four-phase QFD plan, based on a series of matrices that integrate TRIZ inventive principles, a contradiction matrix, and eco-efficiency elements to achieve green-design solutions.



Figure 1. House of Quality.



Deployment of requirements in to SSPs

Figure 2. Example of QFD conceptual model.
Various authors presented decision tools based on the use of QFD principles. Nagahanumaiah, Subburaj and Ravi (2008) presented a rapid tooling process selection based on process capability mapping in quality function deployment (QFD) against a set of tooling requirements that are prioritized through pair wise comparison using Analytical Hierarchal Process (AHP). Lowe, Ridgway and Atkinson (2000) presented a tool developed from the techniques of quality function deployment that allows a rapid evaluation of the feasibility of using the thixoforming process to manufacture products. Chan and $\mathrm{Wu}(2002)$ have listed a broad assortment of examples of works on decision-making based on QFD.

\subsection{Materials Selection based on QFD}

In this paper, it is proposed to perform materials selection at a more technical level than the HoQ, focusing on its latter deployments. In this conceptual model materials selection is performed for each part of the product (e.g. the "SSP Table" on Figure 2), or for some systems or subsystems, when it is feasible.

The proposed materials selector is based on the principles of QFD. The conceptual model, illustrated in Figure 3, divides the procedure into two parts: (1) Assessment Matrix and (2) Selection Matrix. For evaluation purposes of the proposed method, both matrices were applied in a MS-Excel 2010 spreadsheet.

The QFD Method is tool a widely known by industry and its contribution to the product development is already consolidated. However, despite of the simple structure of the method, it involves human intervention and biasness. To reduce uncertainty and improve the reliability of the materials selection method, all data contained on this method, excepting the inputs provided by the designer, are standardized and provided by experts and handbooks.

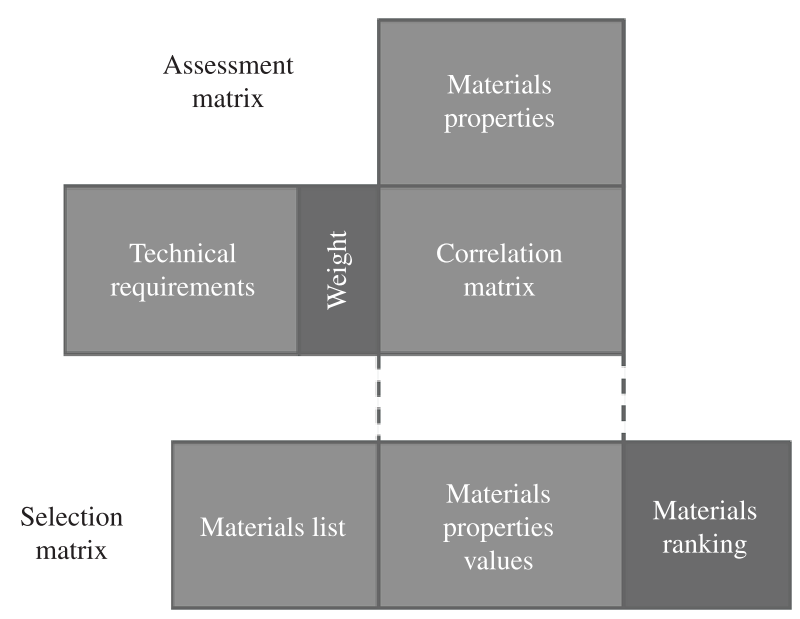

Figure 3. Conceptual Model of the Proposed Materials Selector. 
The Assessment Matrix has for its objective to translate the technical requirements of the part into commonly used materials properties, such as tensile strength, density, thermal conductivity, impact resistance, coefficient of thermal expansion and electrochemical potential.

The proposed method works with standardized technical requirements. These technical requirements have been obtained through the studies of Dornelles Filho and Atolino (2009) on the automotive industry and among projects of a manufacturer of white goods. The technical requirements proposed are illustrated in Figure 4.

The technical requirements should be considered, using for this purpose a scale from 0 to 5 , here called the Requirements Weight, where:

- 5 - the condition of the part is very important to the project;
- 4 - the requirement of the part is important for the project;

- 3 -the requirement of the part is mildly important for the project;

- 2 - the requirement of the part has low importance for the project;

- 1 - the requirement of the part has very low importance to the project; and

- 0 - the requirement doesn't matter to the part.

Apart from the requirements weights, the improvement drivers must also be attributed to the part under analysis, if the technical requirements of parts should be maximized ("must resist risks" = higher is better $=+1$ ) or minimized ("must resist risks" = lower is better $=-1$ ). Requirement Weights and the Improvement Drivers are the only two

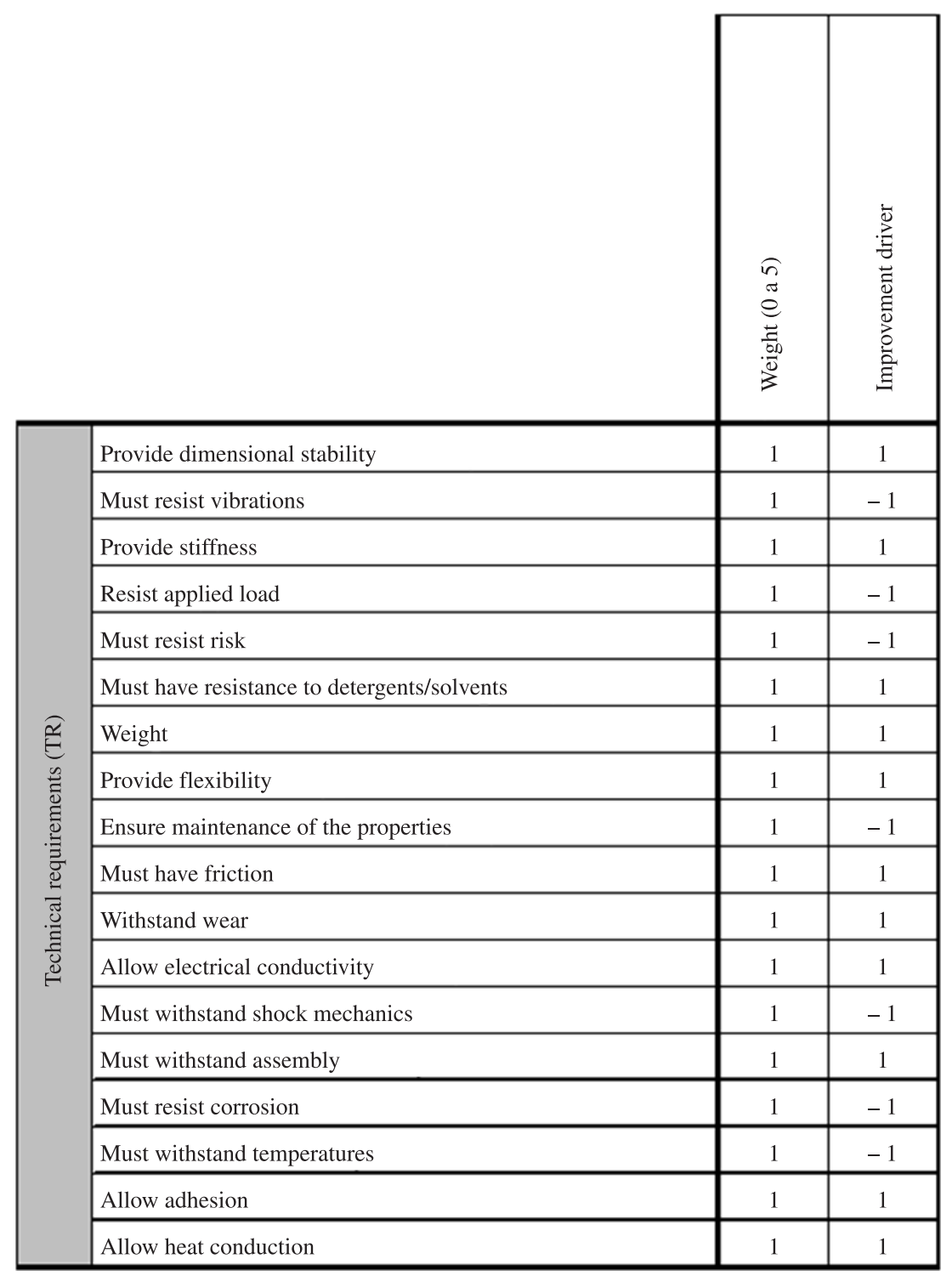

Figure 4. Technical requirements and structure of data entry for its prioritization. 
elements that can be modified by the designers, and all other information of the Selection Matrix is standardized.

A table of materials properties is also provided, focusing on attributes needed to perform the technical requirements gathered for the major appliances industry. The correlation matrix for the Selection Matrix presents the relationship between Technical Requirements and the Materials Properties. Each relationship is weighted by a four-level scale: strong (9 points), moderate ( 3 points), weak (1 point) and null (no points).

A survey was performed among researchers and experts from materials science and engineering areas to fill in the correlation matrix. The gathered data was evaluated and the most common values were included on the final correlation matrix. Thus, the Selection Matrix might be considered a knowledge base and used as presented, but also could be customized for a particular case. Figure 5 presents the proposed Selection Matrix.

Since the information present in the correlation matrix is unvarying, there is only a need to fill in the weights and the improvement drivers for the technical requirements. That done, the relative importance of each material property is automatically calculated using a simple calculation, performed using the weighted sum of the weights and drivers, multiplied by the correlation between the technical requirements and properties of materials. Equation 1 illustrates this process, where $\mathrm{n}$ represents the last Technical Requirement available on the Assessment Matrix. Positive values indicate that the material property must be maximized, and negative properties minimized.

$$
\text { MP importance }=\sum_{\mathrm{i}=1}^{\mathrm{n}} \text { weight } \mathrm{TR}_{\mathrm{i}} \times
$$

improvement driver $\mathrm{TR}_{\mathrm{i}} \times$ correlation index

When in possession of the relative importance of properties, the use of the Selection Matrix shall be initiated, which correlates the materials properties with the materials list. It is important to notice that the values of relative importance for each material property are retrieved from the Assessment Matrix.

This matrix also allows the primary choice, in other words, the prior definition of the materials class, to be used (e.g., polymers, metals, and ceramics). This feature was implemented by filters, which can also limit the range of values of certain properties (e.g., tensile strength must not exceed $50 \mathrm{MPa}$ ).

To allow comparison between different properties, a linear normalization procedure for each material property of the Selection Matrix was adopted, resulting in Equations 2 and 3:

If Property Relative Importance is $\geq 0$, then:

Normalized Value $=\frac{(\text { Property value }- \text { Smallest value })}{(\text { Highest value }- \text { Smallest value })}$

If Property Relative Importance is $<0$, then:

Normalized Value $=\frac{(\text { Smallest value }- \text { Property value })}{(\text { Highest value }- \text { Smallest value })}+1$

The normalized properties will range between 0 and 1 .

The material score is calculated using the sum of each normalized value for the materials properties, plus

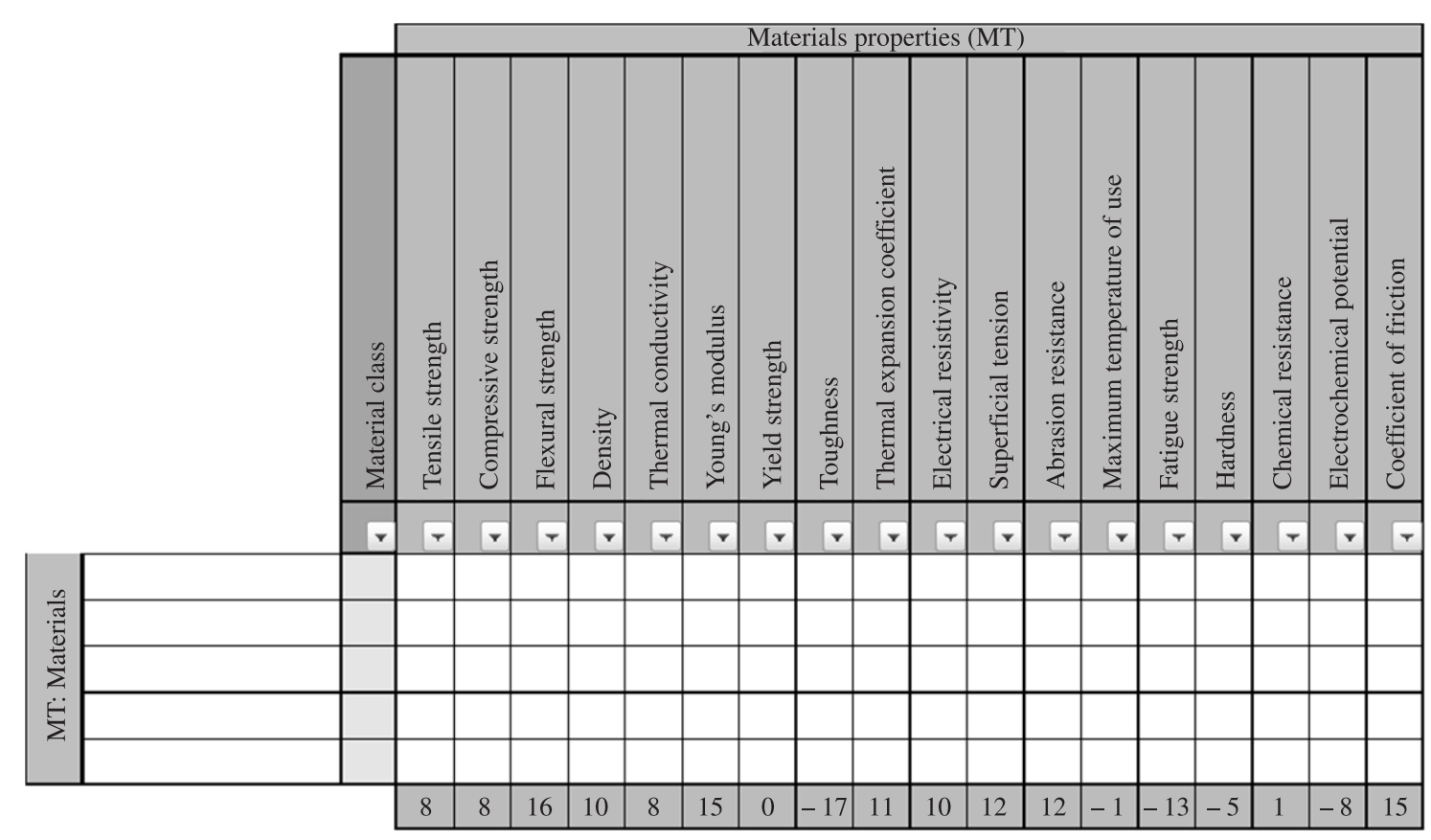

Figure 5. Selection Matrix. 
the correlated importance of each material property (Equation 4). Thus, a ranking among the evaluated materials is provided.

$$
\begin{aligned}
& \text { Material Score }_{i}=\sum_{j=1}^{n}(\text { MP importance })_{j} \times \\
& (\text { normalized property value })_{j}
\end{aligned}
$$

\section{Verification of the proposed method for material selection}

To demonstrate and validate the selection method of materials proposed, one examples from the literature will be used, and the results compared with those from other methods.

This example deals with the selection of the most appropriate material for a cryogenic storage tank for transportation of liquid nitrogen based on DehgnanManshadi et al.(2007). These authors proposed a numerical method for materials selection combining a non-linear normalization method with a modified digital logic and a storage tank used to transport liquid nitrogen as an example. In this study, the same materials and attributes considered by those authors are considered. The performance requirements of the storage tank should be lower density and specific heat, smaller thermal expansion coefficient and thermal conductivity, and adequate toughness at the operating temperature. Also, the material should be sufficiently strong and stiff. Dehgnan-Manshadi et al. (2007) consider six properties: toughness, yield stress, Young's modulus, density, thermal expansion coefficient and thermal conductivity. The candidate materials properties are presented in Table 1.

The first step of the method proposed in the paper is the definition of the weights of the design requirements for completion of the Assessment Matrix. The requirements for material storage tanks to transport liquid nitrogen mentioned by the authors are: toughness and density are the most important properties, and the least important are thermal conductivity and specific heat. Table 2 presents the list of materials requirements mentioned by the authors and the functional requirements of products to be used in this study. The next step is to determine the weights of these requirements and their correlation. The weights were determined based on the importance of material requirements made by Dehgnan-Manshadi (2007), which are also presented in Table 2 .

Once the weights of the product's functional requirements are completed in the Assessment Matrix, the materials are classified automatically in the Selection Matrix. Both matrices used in this example are presented in Figures 6 and 7, respectively. As can be seen in Figure 7, the best material for application in cryogenic tanks is SS301-FH, followed by 3AH-SS310, Inconel 718 and Ti-6AI-4V; this result is similar to the one found by Dehgnan-Manshadi (2007).

Figure 8 and Table 3 presents the results of the classification of materials for the proposed method and other methods in the literature. It is observed that all methods considered SS301-FH as the best material and the worst choices are the aluminum alloys (Al2024-T6, Al5052-O) and the copper alloy $(70 \mathrm{Cu}-30 \mathrm{Zn})$. It can also be noticed that there are small differences in orders between the methods.

Table 1. Properties of candidate materials for cryogenic tank (DEHGNAN-MANSHADE et al., 2007).

\begin{tabular}{|l|c|c|c|c|c|c|}
\hline & Density $\left(\mathbf{g} / \mathbf{c m}^{\mathbf{3}}\right)$ & $\begin{array}{c}\text { Thermal conductivity } \\
\left(\mathbf{c a l} / \mathbf{c m}^{2} / \mathbf{c m} /{ }^{\mathbf{C}} / \mathbf{s}\right)\end{array}$ & $\begin{array}{c}\text { Young's modulus } \\
(\mathbf{M P a})\end{array}$ & $\begin{array}{c}\text { Yield stress } \\
(\mathbf{M P a})\end{array}$ & $\begin{array}{c}\text { Toughness } \\
\text { Thermal expansion } \\
\mathbf{c o e f f i c i e n t}\left(\mathbf{1 0} \mathbf{6}^{\circ} \mathbf{C}\right)\end{array}$ \\
\hline A12024-T6 & 2.80 & 0.370 & 74.2 & 420 & 75.5 & 21.4 \\
\hline A15052-O & 2.68 & 0.330 & 70 & 91 & 95 & 22.1 \\
\hline SS301-FH & 7.90 & 0.040 & 189 & 1365 & 770 & 16.9 \\
\hline SS310-3AH & 7.90 & 0.030 & 210 & 1120 & 187 & 14.4 \\
\hline Ti-6A1-4v & 4.43 & 0.016 & 112 & 875 & 179 & 9.4 \\
\hline Inconel 718 & 8.51 & 0.310 & 217 & 1190 & 239 & 11.5 \\
\hline 70Cu-30Zn & 8.53 & 0.290 & 112 & 200 & 273 & \\
\hline
\end{tabular}

Table 2. Materials requirements vs functional requirements of products and weighting factors.

\begin{tabular}{|l|l|l|c|}
\hline \multicolumn{1}{|c|}{ Material requirements } & & Functional requirements & Weighting factors \\
\hline Thermal expansion coefficient & $\Rightarrow$ & Provide dimensional stability & 3 \\
\hline Stiffness & $\Rightarrow$ & Provide stiffness & 3 \\
\hline Sufficiently strong & $\Rightarrow$ & Resist applied load & 3 \\
\hline Density & $\Rightarrow$ & Weight & 5 \\
\hline Toughness & $\Rightarrow$ & Must withstand shock mechanics & 5 \\
\hline Thermal conductivity & $\Rightarrow$ & Allow heat conduction & 1 \\
\hline
\end{tabular}






\begin{tabular}{|c|c|l|}
\hline \multicolumn{3}{|c|}{ TR: improvement driver } \\
\hline$\Downarrow$ & -1 & Smaller the best \\
\hline$\widehat{\imath}$ & 1 & Greater the best \\
\hline
\end{tabular}

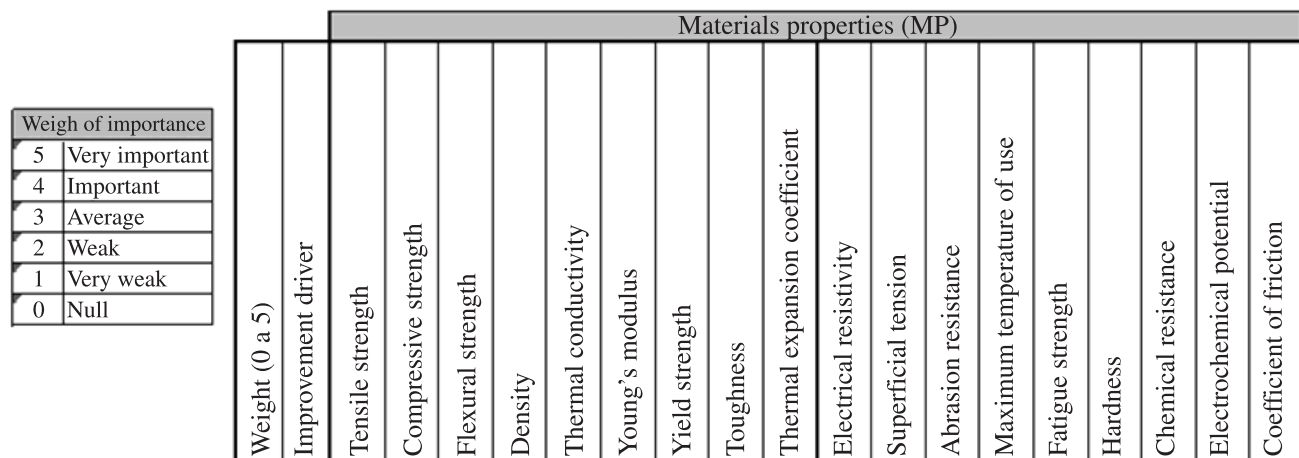

\begin{tabular}{|c|c|c|c|c|c|c|c|c|c|c|c|c|c|c|c|c|c|c|c|c|c|}
\hline \multirow{20}{*}{ 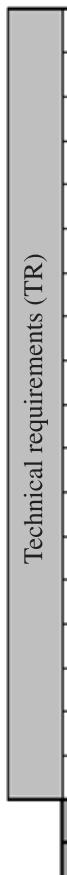 } & Provide dimensional stability & 3 & 1 & - & $\bullet$ & - & 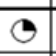 & & - & $\bullet$ & & - & & & ( & $\bullet$ & 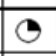 & & & & \\
\hline & Must resist vibrations & 0 & -1 & () & () & () & & & () & & & & & & & & (1) & () & & & \\
\hline & Provide stiffness & 3 & 1 & (1) & ( & (1) & & & - & () & & & & & & (1) & + & (1) & & & \\
\hline & Resist applied load & 3 & 1 & $\bullet$ & $\bullet$ & - & & & - & - & $\bullet$ & $\rightarrow$ & & & & C & (1) & 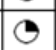 & & & \\
\hline & Must resist risk & 0 & -1 & + & C & + & & & () & & & & & & (1) & & & - & & & \\
\hline & Must have resistance to detergents/solvents & 0 & 1 & & & & & & & & & & & (1) & & C) & & & - & () & \\
\hline & Weight & 5 & -1 & & & & - & & & & & & & & & & & & & & \\
\hline & Provide flexibility & 0 & 1 & + & C & $\bullet$ & & & - & (1) & () & & & & & & & (1) & & & \\
\hline & Ensure maintenance of the properties & 0 & 1 & (1) & ( & (1) & & & - & - & (1) & & & & & $\bullet$ & - & (1) & (1) &  & \\
\hline & Must have friction & 0 & 1 & & & & & & 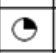 & $\rightarrow$ & & & & & ( & C & & (1) & & & - \\
\hline & Withstand wear & 0 & 1 & & & & & & & & & & & & 0 & ( & & (1) & (1) & 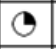 & (1) \\
\hline & Allow electrical conductivity & 0 & 1 & & & & & & & & & & 0 & & &  & & & & & \\
\hline & Must withstand shock mechanics & 5 & 1 & & & & & & & 0 & - & & & & & & & ( & & & \\
\hline & Must withstand assembly & 0 & 1 & - & $\bullet$ & $\bullet$ & & & - & (1) & ( & (1) & & & & & & & & & \\
\hline & Must resist corrosion & 0 & -1 & & & & & & & & & & & & & & & & - & - & \\
\hline & Must withstand temperatures & 0 & 1 & & & & & () & & & & () & & & & $\bullet$ & & & & & \\
\hline & Allow adhesion & 0 & 1 & & & & & & & & & & & - & & & & & () & & () \\
\hline & Allow heat conduction & 1 & -1 & & & & & - & & & & () & + & & & & & & & & \\
\hline & MP relative & oorta & & 63 & 63 & 63 & -42 & \begin{tabular}{|c|}
-9 \\
\end{tabular} & 81 & 68 & $\overline{72}$ & 27 & -1 & 0 & 9 & 39 & 15 & 27 & 0 & \begin{tabular}{|c|}
0 \\
\end{tabular} & $\frac{0}{0}$ \\
\hline & & $\overline{\mathrm{Ral}}$ & & 4 & \begin{tabular}{|l|}
4 \\
\end{tabular} & 4 & 18 & 17 & 1 & 3 & 2 & 8 & 16 & 12 & 11 & 7 & 10 & 8 & 12 & 12 & 12 \\
\hline
\end{tabular}

Figure 6. Assessment Matrix for the cryogenic tank.

\begin{tabular}{|c|c|c|c|c|c|c|c|c|c|}
\hline & &  & 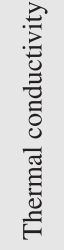 & 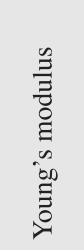 &  & 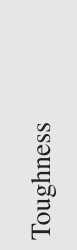 & 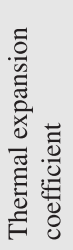 & $\begin{array}{l}0 \\
0 \\
0\end{array}$ & $\begin{array}{l}\text { 昜 } \\
\text { 省 }\end{array}$ \\
\hline \multirow{7}{*}{ 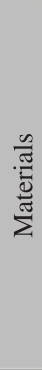 } & Al2024 - T6 & 2.80 & 0.37 & 74.2 & 420.0 & 75.5 & 21.4 & 86.52 & 5 \\
\hline & Al5052 - O & 2.68 & 0.33 & 70.0 & 91.0 & 95.0 & 22.1 & 72.04 & 7 \\
\hline & SS301 - FH & 7.90 & 0.04 & 189.0 & 1365.0 & 770.0 & 16.9 & 234.43 & 1 \\
\hline & $S S 310-3 A H$ & 7.90 & 0.03 & 210.0 & 1120.0 & 187.0 & 14.4 & 167.42 & 2 \\
\hline & $\mathrm{Ti}-6 \mathrm{Al}-4 \mathrm{v}$ & 4.43 & 0.02 & 112.0 & 875.0 & 179.0 & 9.4 & 114.15 & 4 \\
\hline & Inconel 718 & 8.51 & 0.31 & 217.0 & 1190.0 & 239.0 & 11.5 & 162.74 & 3 \\
\hline & $70 \mathrm{Cu}-30 \mathrm{Zn}$ & 8.53 & 0.29 & 112.0 & 200.0 & 273.0 & 19.9 & 73.79 & 6 \\
\hline & & -42 & -9 & 81 & 68 & 72 & 27 & & \\
\hline
\end{tabular}

Figure 7. Selection Matrix of cryogenic tank. 


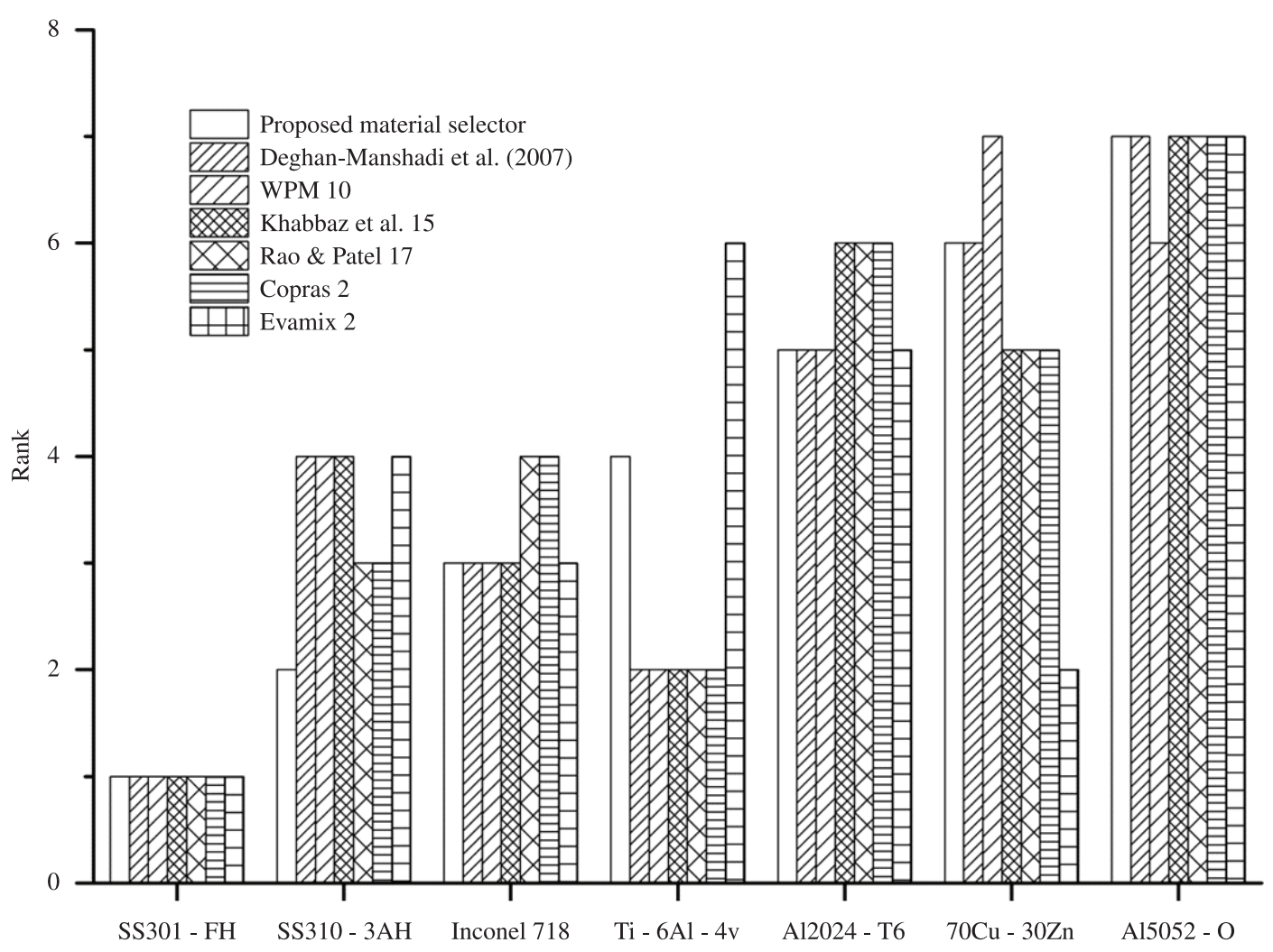

Figure 8. Classification of cryogenic tank materials for different methods

Table 3. Classification of cryogenic tank materials for different methods.

\begin{tabular}{|l|c|c|c|c|c|c|c|}
\hline & $\begin{array}{c}\text { Proposed } \\
\text { material selector }\end{array}$ & $\begin{array}{c}\text { Dehgnan-Manshadi et al. } \\
(\mathbf{2 0 0 7 )}\end{array}$ & WPM $^{\mathbf{1}}$ & $\begin{array}{c}\text { Khabbaz et al. } \\
(\mathbf{2 0 0 9 )}\end{array}$ & $\begin{array}{c}\text { Rao and } \\
\text { Patel (2010) }\end{array}$ & COPRAS $^{\mathbf{2}}$ & EVAMIX $^{2}$ \\
\hline SS301-FH & 1 & 1 & 1 & 1 & 1 & 1 & 1 \\
\hline SS310-3AH & 2 & 4 & 4 & 4 & 3 & 3 & 4 \\
\hline Inconel 718 & 3 & 3 & 3 & 3 & 4 & 4 & 3 \\
\hline Ti-6Al-4v & 4 & 2 & 2 & 2 & 2 & 2 & 6 \\
\hline Al2024-T6 & 5 & 5 & 5 & 6 & 6 & 6 & 5 \\
\hline 70Cu-30Zn & 6 & 6 & 7 & 5 & 5 & 5 & 2 \\
\hline Al5052-O & 7 & 7 & 6 & 7 & 7 & 7 & 7 \\
\hline
\end{tabular}

${ }^{1}$ Farag (1997). ${ }^{2}$ Chatterjee, Athawale and Chakraborty (2011).

Considering these results it is important to notice that for this example, the method based on QFD, despite all its simplicity and ease of implementation, has proved to be able to classify the candidate materials under similar conditions compared to the existing literature, which are much more complex.

\section{Conclusion}

The complexity of current materials selection methods is a barrier for implementing these processes in a broad number of enterprises, which prefers to rely on the expertise of their engineers. On the other hand, this decision could reduce possibilities of materials innovation in some cases. The use of QFD tools is seen as a way to turn the use of design tool simple and more attractive, since is broadly known and used by industry.

However, QFD tools are usually involves human intervention and biasness. To reduce this uncertainty and improve the reliability of the proposed materials selection method, human interaction was reduced to a minimum through the inclusion of information provided by materials engineering experts. The only information provided by the designer are the part technical requirements, which also were standardized, and its improvement drivers.

The examples' results demonstrated the simplicity and reliability of the proposed method. The proposed procedure has presented results consistent with the literature, 
demonstrating that the use of expert knowledge in the area is a viable path to material selection.

\section{Acknowledgements}

The authors are grateful to Whirlpool for technical support and UDESC for financial support.

\section{References}

AKAO, Y. Quality Function Deployment: Integrating Customer Requirements into Product Design. Cambridge: Productivity Press; 1990.

ASBHY, M. F. Materials selection in conceptual design. Material science and Technology, v. 5, p. 517-525, 1989. http://dx.doi.org/10.1179/026708389790222735

ASHBY, M. F. Materials selection in mechanical design. Oxford: Pergamon Press, 1992.

CHAKRABORTY, S.; DEY, S. QFD-based expert system for non-traditional machining processes selection. Expert Systems with Applications, v. 32, p. 1208-1217, 2007. http://dx.doi.org/10.1016/j.eswa.2006.02.010

CHAN, L.-K.; WU, M.-L. Quality function deployment: A literature review. European Journal of Operational Research, v. 143, p. 463-497, 2002. http://dx.doi. org/10.1016/S0377-2217(02)00178-9

CHATTERJEE, P.; ATHAWALE, V. M.; CHAKRABORTY, $\mathrm{S}$. Materials selection using complex proportion assessment and evaluation of mixed data methods. Materials and Design, v. 32, p. 851-860, 2011. http://dx.doi.org/10.1016/j. matdes.2010.07.010

CHATTERJEE, P.; ATHAWALE, V. M.; CHAKRABORTY, S. Selection of materials using compromise ranking and outranking methods. Materials and Design, v. 30, p. 4043-4053, 2009. http://dx.doi.org/10.1016/j.matdes.2009.05.016

CHEN, C. C.; YEH, T. M.; YANG, C. C. Performance measurement for new product development: a model based on total costs. International Journal of Production Research, v. 44, p. 4631-48, 2006. http://dx.doi. org/10.1080/00207540500517756

CHEN, S.-M. A new method for tool steel materials under fuzzy environment. Fuzzy Sets and Systems, v. 92, p. 265-274, 1997. http://dx.doi.org/10.1016/S01650114(96)00189-3

CHENG,L.C.; MELOFILHO,L.D.R. BuildingConceptual Models in QFD. In: INTERNATIONAL SYMPOSIUM ON QUALITY FUNCTION DEPLOYMENT -ISQFD'08-Beijing, 14., 2008, Beijing. Proceedings... Beijing, 2008.

CHENG, L. C.; MELO FILHO, L. D. R. QFD: Desdobramento da Função Qualidade na Gestão de Desenvolvimento de Produtos. São Paulo: Editora Blucher, 2007.
DEHGNAN-MANSHADI, B. et al. A novel method for materials selection in mechanical desing: Combination of non-linear normalization and modified digital logic method. Materials and Design, v. 28, p. 8-15, 2007. http://dx.doi. org/10.1016/j.matdes.2005.06.023

DENG, Y.-M.; EDWARDS, K. L. The role of materials identification and selection in engineering design. Materials and Design, v. 28, p. 131-139, 2007. http://dx.doi. org/10.1016/j.matdes.2005.05.003

DORNELLES FILHO, A. M. L.; ATOLINO, W. J. T. Plásticos de Engenharia: Seleção eletrônica no caso automotivo (Engineering Plastics - Electronics selection in automotive case). São Paulo: Artiliber, 2009.

ESAWI, A. M. K.; ASHBY, M. F. Systematic process selection in mechanical design. In: ASME DESIGN ENGINEERING TECHNICAL CONFERENCE; 1996; Irvine. Proceedings... Irvine, 1996. p. 1-8.

FARAG, M. M. Materials selection for engineering design. Prentice-Hall, 1997.

FERRANTE, M.; SANTOS, S. F.; CASTRO, J. F. R. Materials Selection as an interdisciplinary technical activity: Basic methodology and case studies. Materials Research, v. 3, p. 1-9, 2000. http://dx.doi.org/10.1590/S151614392000000200002

JAHAN, A. et al. Material selection based on ordinal data. Materials and Design, v. 31, p. 3180-3187, 2010. http:// dx.doi.org/10.1016/j.matdes.2010.02.024

KHABBAZ, R. S. et al. A simplified fuzzy logic approach for materials selection in mechanical engineering design. Materials and Design, v. 30, p. 687-697, 2009. http:// dx.doi.org/10.1016/j.matdes.2008.05.026

LIAO, T. W. A fuzzy multicriteria decision-making method for material selection. Journal of Manufacturing System, v. 15, p. 1-12, 1996. http://dx.doi.org/10.1016/02786125(96)84211-7

LJUNGBERG, L. Y.; EDWARDS, K. L. Design, materials selection and marketing of successful products. Materials and Design, v. 24, p. 519-529, 2003. http://dx.doi. org/10.1016/S0261-3069(03)00094-3

LOWE, A.; RIDGWAY, K.; ATKINSON, H. QFD in new production technology evaluation. International Journal of the Production Economics, v. 67, p. 103-112, 2000. http:// dx.doi.org/10.1016/S0925-5273(99)00125-5

MAYYAS, A. et al. Using Quality Function Deployment and Analytical Hierarchy Process for material selection of Body-InWhite. Materials and Design, v. 32, p. 2771-2782, 2011. http://dx.doi.org/10.1016/j.matdes.2011.01.001

NAGAHANUMAIAH; SUBBURAJ, K.; RAVI, B. Computer aided rapid tooling process selection and manufacturability evaluation for injection mold development. Computers 
in Industry, v. 59, p. 262-276, 2008. http://dx.doi. org/10.1016/j.compind.2007.06.021

RAHIMI, M.; WEIDNER, M. Integrating Design for Environment (DfE) Impact Matrix into Quality Function Deployment (QFD) Process. The Journal of Sustainable Product Design, v. 2, p. 29-41, 2002. http://dx.doi. org/10.1023/B:JSPD.0000016418.79201.e7

RAO, R. V.; PATEL, B. K. A subjective and objective integrated multiple attribute decision making method for material selection. Materials and Design, v. 31, p. 4738-4747, 2010. http://dx.doi.org/10.1016/j.matdes.2010.05.014
RAO, R. V. A material selection model using graph theory and matrix approach. Material Science and Technology, v. 431, p. 248-255, 2006.

SANTOS, S. F.; FERRANTE, M. Selection methodologies of materials and manufacturing processes. Materials Research, v. 6, p. 487-492, 2003. http://dx.doi.org/10.1590/ S1516-14392003000400010

YEH, C. H.; HUANG, J. C. Y.; YU, C. K. Integration of four-phase QFD and TRIZ in product R\&D: a notebook case study. Research in Engineering Design, v. 22, p. 125-141, 2011. http://dx.doi.org/10.1007/s00163-0100099-9 